ERC Working Papers in Economics 16/14

December / 2016

\title{
Socio-Economic Factors Affecting Early Childhood Health: The Case of Turkey
}

\author{
Deniz Karaoğlan \\ Department of Economics, Bahçeşehir University, İstanbul, Turkey \\ E-mail: hanifedeniz.karaoglan@eas.bau.edu.tr
}

\author{
Dürdane Șirin Saracoğlu \\ Department of Economics, Middle East Technical University, Ankara, Turkey \\ E-mail: ssirin@metu.edu.tr \\ Phone: + (90) 3122102058
}




\title{
SOCIO-ECONOMIC FACTORS AFFECTING EARLY CHILDHOOD HEALTH: THE CASE OF TURKEY*
}

\author{
Deniz KARAOĞLAN** \\ Bahcesehir University, Department of Economics, 34349 Istanbul \\ e-mail: hanifedeniz.karaoglan@eas.bau.edu.tr
}

\author{
Dürdane Şirin SARAÇOĞLU \\ Middle East Technical University, Department of Economics, 06800 Ankara \\ e-mail:ssirin@metu.edu.tr
}

\begin{abstract}
In this study we examine the association between parents' socioeconomic status (SES) and childhood health in Turkey, a middle income, developing country using the 2013 round of Demographic Health Survey (DHS) data set. In our investigation, we focus on children from 7 to 59 months old and as a measure of health status, we use the height-for-age z-score, which is the measure of stunting and wasting. In order to overcome the biases with respect to age and gender, we calculate the child's standardized height measure. Using classical regression techniques, after controlling for the child's birth order, birth weight, mother's height, mother's breastfeeding, nutrition status and pre-school attendance, the impact of parent's SES on child's health measures is assessed, and parents' SES indicators include region of residence, number of household members, father's presence, parents' education and work status, and household wealth index based on the household's asset holdings. Our results indicate that while mother's education and occupation type are among the leading factors that affect the child's health status, urban residence appears to be the dominant factor which positively affects child's health: SES of families proxied by living conditions and infrastructure factors such as sanitation, access to clean water, availability of electricity, which are under the control of local governments, as well as access to health care services must be improved for better child health.
\end{abstract}

JEL Classification codes: C20; I15; J13

Keywords: Health, children, z-score, household socioeconomic status, Turkey

\footnotetext{
* Authors would like to thank Meltem Dayığlu-Tayfur for invaluable suggestions and comments.

** Corresponding author
} 


\section{Introduction}

Extensive empirical evidence from the modern economic growth literature has determined that human capital is a crucial component in attaining a sustainable economic growth path, and countries which were able to raise their human capital stock have been able to move up in the world income distribution and thus have experienced convergence with the relatively richer, developed economies regarding their standards of living (e.g. Mankiw et al. 1992; Benhabib and Spiegel 1994; Barro 2001; Cohen and Soto 2007). In economics, human capital formation is broadly conceptualized to include education, health, on-the-job training, migration and other investments into an individual to enhance that individual's productivity (Schultz 1961; Becker 1962; Mushkin 1962). In fact, investment expenditures made particularly on education and health services yield a continuing return to the individual in the future (Mushkin 1962) and the earlier the investment, the longer will be the period over which the individual can benefit from this early investment as higher returns on past investment are realized (Becker 1962; BenPorath 1967). Furthermore, studies show that the rate of return to investment in human capital as a function of age is highest when investment is made at younger ages and early investments improve the return on subsequent investments (Carneiro and Heckman 2003; Knudsen et al. 2006; Heckman and Masterov 2007; Conti and Heckman 2012).

That being said, Grossman $(1972,2000)$ argues that health capital differs from other forms of human capital, and that while education and accumulation of knowledge directly affects an individual's market and non-market productivity, health is a durable capital stock that determines the amount of healthy time the individual can spend producing. According to Grossman, each individual starts life with a given stock of health which depreciates with age, and which can be enhanced through investment. Accordingly, an increase in the stock of health through investment would reduce the time lost from market and non-market activities, and the monetary return on this reduction is an indicator of the return to an investment in health. Considering that health capital cannot be excluded from the measures of human capital and that it has a crucial impact on economic well-being, ${ }^{1}$ multiple cross-country studies provide empirical evidence for the affirmative wage and income effects of better adult health status (e.g. Arora, 2001; McDonald and Roberts 2002; Shastry and Weil 2003; Gyimah-Brempong and Wilson 2004; Schultz 2002, 2003, 2005; and Liu et al. 2008 for China).

\footnotetext{
${ }^{1}$ However one must still be cautious to consider the endogeneity in income and health, or the direction of causality: relationship also may run from income/wealth and higher socioeconomic status to better health (Adler et al. 1994; Meer et al. 2003).
} 
Inspired by the recent research over a range of different disciplines examining the long-term effects of early childhood conditions, economists also came to realize that early life circumstances leading to differences in human capital may have persistent and intense effects in adult life (Almond and Currie 2010). While there may be many diverse factors determining the individual's background, one crucial factor that stands out in the literature is childhood health (Currie 2009). In this respect, Case et al. (2005) using long-term data from the Great Britain and Smith (2009) from the US study the impact of childhood health on later life outcomes: according to their estimation results, an individual's general health status during childhood has significant and profound direct and indirect effects on adulthood socioeconomic status indicators, such as the ability to earn in the labor market (through the completed years of schooling), total family income, and wealth. In this sense, health appears to be an important link in the intergenerational transmission of socioeconomic status: children born into poorer families experience poorer childhood health status, lower investments into human capital and poorer health in early adulthood, ultimately leading to lower earnings in adulthood (Blau 1999; Case et al. 2002, 2005; Currie 2009). Previous literature thus indicates that part of intergenerational transfer of socioeconomic status or mobility of income within families may work through the impact of parents' socioeconomic status on children's health (Case et al. 2002).

As explained above, for adults, health has a significant impact on economic well-being, through its wage and income effects. Nevertheless, as Adler et al. (1994) and Meer et al. (2003) suggest, the causality, if there is any, may run both ways: there may be a two-way causality between health and income for adults, as higher income may cause better health (individuals with more wealth can afford better medical care, live in healthier environments, etc.) or better health may lead to higher income (healthy individuals may be able to work more than those who are not, therefore earn higher income and amass more wealth). However, as Case et al. (2002) explain, such endogeneity will not materialize for young children, since in general young children do not contribute to household income, therefore their lower child health status cannot explain lower household income. Consequently, by focusing on children, the mechanism that runs from health to income is eliminated, and thus investigating the impact of family income and SES on child health provides clear and consistent conclusions about the association.

In the light of these arguments, in the current study we explore the impact of family's socioeconomic status on childhood health in Turkey, a middle income, developing country, using the 2013 round of Turkey Demographic Health Survey (DHS) data set, which is the most 
recent DHS data set available for Turkey. To our knowledge, except for Güneş (2015) which explores the causal effect of maternal education on child health in Turkey using DHS for 2008, this will be the first attempt to investigate the effects of parents' full range of socioeconomic status indicators on the child's physical health outcomes by using a rich micro data set for Turkey. We focus on children 7 to 59 months old (59-month-old children are included) and use their anthropometric measures as measures of health outcome, specifically the height-for-age $\mathrm{z}$-score, which is the measure of stunting and wasting. We restrict our sample to children 7 to 59 months old so that we can control for the effects of differences in nutrition intake in addition to those with respect to mother's breastfeeding on child's health outcome. We use standardized height as the measure of childhood health in order to avoid the biases due to gender and age differences between children. In this study, we calculate standardized height for each child from 7 to 59 months old by using LMS (Lambda Mu Sigma) coefficients from the 2006 World Health Organization (WHO) Growth Reference. Using classical regression techniques, after controlling for the child's birth order, birth weight, mother's height, mother's breastfeeding, nutrition status and pre-school attendance, we assess the effects of family's socioeconomic status indicators including the region of residence, number of household members, father's presence, parents' education level and work status, and household wealth, on child's anthropometric measures.

Our results indicate that living in urban areas is a dominant factor that improves the child's health status in Turkey. This result implies that convenient access to health care services as well as living conditions and infrastructure factors such as sanitation, access to clean water, availability of electricity, which are more readily available in urban areas, consistently affects the child's health outcomes positively, regardless of the other SES factors. In addition, we find that mother's education is generally a leading factor in child's health status: more educated mothers have access to information for better health, and they make better use of available health care services for their children. We also observe that children of unemployed mothers as well as the children of irregular self-employed and unpaid family worker mothers are in a worse health condition compared to other occupation groups. Having said that, fathers' education level and employment status are found to be insignificant in determining child's health condition, an outcome which is also prevalent in the literature. Next, our results suggest that proper nutrition is necessary for better child health outcomes. Finally, we observe that child's exogenous factors at birth, such as birthweight and birth order are significant determinants of child's future health. The rest of the study is organized as follows. In Section 2 we review the literature on the 
relationship between family's socioeconomic status and childhood health. A description of the Turkey DHS-2013 data and the methodology by which we construct the anthropometric measures are provided in Section 3. Section 4 presents the estimation strategy and the model results. Finally, Section 5 concludes the study with some policy implications.

\section{Background}

There is a large body of research attempting to assess the association of family's socioeconomic status with a wide range of health, cognitive, and socioemotional outcomes in children (e.g. among many, Hauser 1994; Duncan et al. 1994; Aber et al. 1997; Brooks-Gunn and Duncan 1997; Blau 1999; Bradley and Corwyn 2002; Taylor et al 2004; Chen 2004; Maggi et al. 2010). Family's material resources such as family purchasing power, family income, father's income, or the principal earner's income are considered to be the primary determinants of a family's socioeconomic status. Mother's educational attainment, mother's occupational status, family type (nuclear or extended), family size or density (number of persons per room), number of children in the family and parental cohabitation are among other critical factors taken into account in the literature to quantify the socioeconomic status of a family. Additionally, the family's physical environment in terms of household and neighborhood sanitary infrastructure (i.e. housing quality, water supply, sanitation, garbage disposal, sewage disposal, paving), is an essential indicator of a family's socioeconomic status. The general consensus in these studies is that family's SES has profound effects on child outcomes, and that early child development lays the foundation for health conditions, well-being, learning and cognitive skills acquired in the course of one's life.

A closely related but separate strand of literature in economics and child development associates parents' income and SES exclusively with child's health status. More specifically, according to Aber et al. (1997), children who are persistently exposed to poverty are at a higher risk for multiple adverse health outcomes, including low birthweight and infant mortality, and for the children who survive past their first year of life, neurological and psychological developmental problems and other health-related problems such as iron deficiency and stunting may arise. Likewise, Currie and Hyson (1999) argue that babies born into low SES families are born with low a birthweight and the negative consequences of low birthweight persist as these children get older. Furthermore, Case et al. (2002) show that children from low income families have a relatively worse health status compared to those from high income families, and the 
authors suggest that the positive association between parents' income and the child's health becomes more obvious as the child becomes older. Hence, poor childhood health status persists in the long-run. In fact, from a public health policy perspective, children from low SES backgrounds not only sustain greater health problems at childhood, but they experience poorer health outcomes as adults since aspects of their SES become biologically integrated through both critical periods of development and cumulative effects (von Rueden et al. 2006; Conroy et al. 2010). Case et al. (2005) also determine that children born into poorer families experience poorer health in adolescence and lower investments in human capital, and this leads to lower earnings in their adult years.

In addition to parental income, or other pecuniary earnings, in most of the previous literature, parental, particularly maternal education is also considered to be an important factor that is associated with better childhood health status, as educated mothers possess the ability to understand and apply new methods of child care (Thomas et al. 1991; Desai and Alva 1998; Glewwe 1999; Finch and Beck 2011). In fact, Wamani et al. (2004) demonstrate that what matters for inequalities in child health conditions is the mothers' education, rather than fathers' education, as in the case for a developing country such as Uganda. ${ }^{2}$ Correspondingly, Glewwe (1999) establishes the mechanisms by which maternal education positively affects child health: (i) through formal education, future mothers get better informed about health knowledge; (ii) educated mothers are more capable of diagnosing and treating and child health problems with the literacy and numeracy skills they acquired at school; and (iii) mothers with formal schooling would be more open to modern medical treatments. In related studies, parents' employment status and occupation type (e.g. manual skilled, semi-skilled, unskilled, or managerial jobs) are also used as indicators for parents' SES (for example Case et al., 2005). Furthermore, some studies also point out that child's health is also affected by parents' health related behavior in prenatal period, i.e. cocaine, nicotine and alcohol consumption (Case et al. 2005; Case and Paxson 2002).

The research discussed above largely examines the relationship between parents' SES and childhood health in developed countries such as US, UK, or other European countries. There are also similar studies conducted for the developing economies and in general, they also find a positive association between household SES and child's health (see for instance, Durkin et al.

\footnotetext{
${ }^{2}$ Nevertheless, Thomas (1994) using cross-country data from the US, Brazil and Ghana, demonstrates that mother's education has a bigger effect on daughter's height, while father's education has a bigger impact on son's height as a status of health measure.
} 
1994; Desai and Alva 1998; Zere and McIntyre 2003; Grantham-McGregor et al. 2007; Wamani et al. 2007; Chen and Li, 2009; Amin et al. 2010, Abuya et al. 2012; Zong et al. 2015). The analyses for the developing countries predominantly use Demographic and Health Surveys (DHS) within which the child's anthropometric measures are available. Hence with this availability, most of these studies use indicators of stunting (excessively low height for one's age) and wasting (excessively low weight for one's height), such as z-scores of height-for-age to represent childhood health status, as opposed to family's self-reported health status as in most of the research in developed countries. Both inadequate food intake and an inability to absorb or assimilate nutrients due to disease or infections lead to malnutrition, hence signals of malnutrition such as stunting and wasting are good gauges of child's overall health (Assaad et al. 2012). Therefore, the studies on developing countries provide a more objective perspective on the impact of parental socioeconomic factors on child's health in contrast to the studies in developed countries, where for the most part child's self-reported health or self-reported chronic illnesses by parents represent child's health outcome.

\section{Data and Descriptive Statistics}

For this study, we use the 2013 round of Demographic Health Survey (DHS) data set for Turkey. In Turkey, DHS data sets are prepared by Hacettepe University, Institute of Population Studies. The survey contains a rich set of demographic variables regarding children and their parents. For children we can observe several anthropometric measures such as birth order, birthweight, height and weight as well as their breastfeeding status and nutrition. We are also able to determine whether the child attends pre-school/crèche or not. The survey also gathers information about the parents' completed education level, employment statuses, occupation types and household wealth. Therefore, DHS provides a good setting to examine the impact of the parents' socioeconomic status on the child's health. The results of the survey have been revealed every five years since 1993 and the 2013 version is the most recent version of DHS.

As both household and individual (females in the household) data sets are available in DHS to the users, we firstly merge these two data sets by cluster number, household number and respondent's line number and we end up with 5928 female observations, for which household variables are available. We restrict our sample to females with children between 7 and 59 months old in order to be able to assess the effects of nutrition variations and breastfeeding on child's health outcome (infants 0-6 months old are only breastfed or are given infant formula, 
hence do not present any variation in nutrition). Out of those 5928 observations, 1867 women have one, 498 women have two, 54 women have three, five women have four and one woman has five children between 7 and 59 months old. Consequently, our sample consists of 2425 children who are between 7 and 59 months old ${ }^{3}$.

\subsection{Dependent Variable: Standardized Height}

To represent child health outcomes, studies regarding childhood health status in developed countries use self-reported health of the child (chronic and acute health conditions, number of doctor visits, and hospital stays, etc.) which is reported by a parent or a physician, or both. However, Case et al. (2002) suggest that infant mortality rates, anthropometric measures, and indicators of vaccination are better signs for child health status. Furthermore, Assaad et al. (2012) claim that malnutrition in childhood is indicative of the child's health in general, and point out that anthropometric indicators of stunting and wasting, such as height-for-age zscores, characterize both long-term and short-term malnutrition for children under five years old. Following Assaad et al. (2012), the childhood health outcome in our analysis is represented by the standardized height of the child, which is derived from the child's height-for-age zscore $^{4}$.

In order to calculate the child's standardized height, firstly we compute the height-for-age zscore for each child between 7 and 59 months old. A z-score describes how far and in what direction an individual's anthropometric measurement deviates from the median provided in 2006 WHO Child Growth Standard for his/her gender. We compute the height-for-age z-score in the following manner:

$$
z_{-} \text {score }=\frac{X-M}{\sigma}
$$

In equation (1), $X$ refers to the observed measure (i.e. the child's measured height), $M$ refers the median value of the reference population and $\sigma$ refers to the standard deviation value of the reference population (i.e., median and standard deviation of the measured heights of the same

\footnotetext{
${ }^{3}$ The sample sizes may get smaller in different estimations because we may not observe some control or dependent variables in the selected sample. It is explained in detail in the following sections.

${ }^{4}$ We do not use standardized anthropometric measures related to weight (such as weight-for-age) due to three reasons: first, higher weight does not imply better health. Second, thinness does not necessarily imply health risk. Third, previous research shows that the models using household or demographic surveys better explain height than weight (Pradhan et al. 2003).
} 
age and gender group of children). We omit the observations where the child has a z-score less than -7 or more than 7 , as they are considered to be outliers. After factoring out the observations in which child's height information is missing, we are left with 1921 observations of children between 7 and 59 months old ${ }^{5}$.

Next, we use LMS (Lambda Mu Sigma) coefficients from 2006 WHO Growth Reference for the 24-month-old female in order to standardize the height of each child as if he/she were a 24month-old female in order to avoid the biases that may occur due to differences in gender and age (Assaad et al. 2012). We calculate the standardized-height of the child as follows:

$$
\text { Standardized_Height }=M \times \sqrt[L]{1+L \times S \times z_{-} \text {score }}
$$

Regarding the LMS coefficients, L shows the power in the Box-Cox transformation for correcting the skewness, $\mathrm{M}$ refers to median and $\mathrm{S}$ is the coefficient of variation. All of the variables in equation (2) are constants, except the z-score of each child. We take the constant LMS values for a 24-month-old female such that $\mathrm{L}=1, \mathrm{M}=85.7153$ and $\mathrm{S}=0.03764$ and calculate the standardized-height of each child between 7 and 59 months old.

\subsection{Explanatory Variables}

DHS data set contains rich information on the child's anthropometrics, nutrition indicators, preschool/crèche attendance, region, parents' socioeconomic status and household wealth. In this section, we elaborate on the factors which may be associated with the child's health outcome.

\section{Child's Anthropometrics and Mother's Height}

In DHS data set we observe the child's age (in months) and gender. We compute the heightfor-age z-score and the standardized-height of the child by using the information on age and gender variables. However, we do not include the indicators of age and gender in our regression analysis since the height of each child is already standardized to a 24-month-old female. In the empirical analysis we include the two major anthropometric measures: child's birthweight ${ }^{6}$ and birth order. The questions regarding birthweight and birth order of each child are asked to mothers and their answers are recorded. We use these records directly in our empirical analysis.

\footnotetext{
${ }^{5}$ We calculate the height-for age z-scores by using zscore06 command in STATA, version 13.0.

${ }^{6} \mathrm{~A}$ recent study explores the changes in associations between birthweight and height over different life stages (Krishna et al. 2016).
} 
The height of the child may be affected from the heights of both parents due to genetics. In order to control for, at least some part of, the genetic factors, we also control for mother's height. Mother's height is available in the DHS data set, however we cannot observe the height of the father.

\section{Nutrition Indicators}

We include two nutrition indicators for each child in the empirical analysis. The first nutritional intake variable is related to breastfeeding. We create a dummy variable which indicates whether the child is (or was ever) breastfed. The variable is equal to 1 if the child is breastfed during some time in his/her early life, and is equal to 0 otherwise.

The second variable for nutritional intake is the "Nutrition Index" which we construct based on the food groups that are fed to the children. From the DHS data set we are able to observe whether the child is fed a from total of 12 nutrition groups such as fruit and vegetables, cereals and grains, yoghurt, cheese, red meat, poultry, dry legumes, cow's milk, whole eggs, fish, bread, and soups. In DHS, the mother is asked whether the child has acquired any of these types of nutrition in the last 24 hours. However, it is important to note that most food groups are agespecific and infants at different age groups (particularly up to 18 months of age) acquire nutrition from a different number of food groups; a child younger than 18 months cannot absorb or assimilate all nutrition types. Table 1 summarizes the nutrition that is appropriate to be fed to infants and children at different ages based on Sears and Sears (2003):

\section{<Table 1. Infant feeding and food groups in Turkey DHS 2013> about here}

In order to calculate the nutrition index for each child, first, we assign 1 or 0 to each group of nourishment depending on whether the child has acquired that food group or not in the last 24 hours. For example, if a child has been fed fresh vegetables and fruits in the last 24 hours, the dummy variable for that food group is equal to 1 for that child, 0 otherwise. If the child is 7 months old, all the dummies are missing for food groups other than fresh vegetables fruits along with cereals and grains since the child cannot be fed the other nutrition groups when he/she is just 7 months old (Table 1). We define the dummies of each food group in the similar way based on information given in Table 1 . Then we equally weigh each type of nutrition and take the average of nutrition group dummies. For instance, if the child is 7-9 months old, the nutrition index is equal to the average of the dummy variable for fresh vegetables and fruits and the dummy variable for cereals and grains, or if the child is older than 18 months old, we simply 
sum up the dummies for all food categories and then divide this summation by 12 (if the child is 18 months or older, he/she can take all nutrition types). Accordingly, we generate a proper nutrition index within the range $[0,1]$ for each child independent of his/her age.

\section{Child's pre-school/crèche attendance}

In the DHS data set, we observe whether the child participates in an early childhood development program in a pre-school/crèche or not. By attending pre-school/crèche, the child is expected to receive professional and age-appropriate educational, health and nutritional services which support his/her growth and development (e.g. Anderson et al. 2003). Furthermore, child care professionals in a pre-school/crèche are expected to be better equipped to recognize any specific health problem of the child, and inform and advise the parents for immediate and appropriate medical care. In order to test the effect of pre-school attendance on child's health, we define a dummy variable which is equal to 1 if the child attends pre-school or crèche, it is equal to 0 if he/she does not.

\section{Region}

The region where the household lives (urban/rural) is available in the DHS data set. We create a dummy variable for the region where the household lives. The variable is equal to 1 if the household resides in an urban area, and is 0 if the household resides in a rural area. We expect that the region variable has a significant impact on the child's health since living conditions and infrastructure factors such as sanitation, access to clean water, availability of electricity, as well as convenient access to health care services which are more prevalent in urban areas, directly influence the child's health status.

\section{Wealth Index}

Previous literature on developed countries uses household's wealth as the main determinant of the parents' socioeconomic statuses. In DHS data sets, unfortunately, we cannot observe household income or consumption expenditures. Instead, we are able to observe a wealth index variable, which is constructed by using principal components analysis (PCA) following Filmer and Pritchett (2001) based on household's asset holdings (for instance, whether the household owns a car, has access to clean water, toilet facility, electricity, etc). The wealth index ranges from 1 to 5 (a discrete variable) and each wealth index proxies for a corresponding income quantile. 


\section{Parents' Education Levels}

Parents' education levels are used widely as indicators of socioeconomic status in the literature and especially the mother's education level has a significantly affirmative impact on child's health. In DHS data set, we are able to observe the years of schooling completed by both the mother and the father, and we directly use this information.

\section{Parents' Employment Statuses}

Parents' employment statuses (employed, unemployed and inactive) and occupation types (employer, regular wage-earner, unpaid family worker, regular/irregular self-employed, etc.) also reflect their socioeconomic status and they are expected to have a significant impact on the child's health outcome. For fathers, we create three dummy variables, identified as 'employed', 'unemployed', and 'inactive'. For instance, the variable 'employed' is equal to 1 if the father is employed and it is equal to 0 if he is unemployed or inactive. Other dummy variables for fathers' employment statuses are defined in similar way. The omitted category in the regression analysis is 'inactive'.

For mothers, in addition to the employment status (employed, unemployed, inactive), we also take the occupation status of the mother into account if she is employed. We attribute significance to mother's occupation type since we do not expect that being employed as an unpaid family worker will have the same effect as, for example, being employed as a regular wage earner on the child's health outcome. We define dummy variables for each occupation type as well as the employment statuses, and similar to father's employment statuses, for mothers we also exclude the variable 'inactive' from regression analysis.

We also control for the possible high correlation between parents' education levels and employment statuses and we find out that the correlation is not as high as we expected (around 0.20 for mothers and 0.10 for fathers). Moreover, we also calculate the variance inflation factor (VIF) of each education and employment variable and find that the VIF is less than the threshold level of 10 for those variables. Therefore, there is no risk of multicollinearity in the regressions when we include the parents' both education levels and employment statuses.

\section{Other Indicators of Socioeconomic Status}

In the empirical analysis, we consider other certain factors that may reflect information regarding parents' socioeconomic status, such as the number of household members, ethnicity, and female headship. The number of household members of each household is provided in the 
DHS data set and we directly use this information.

For female headship, we define a dummy variable which is equal to 1 if the female reports that she is the household head, and is 0 otherwise, i.e. the father is present and is reported as the household head.

In the DHS data set, the mother tongues of females are available. Therefore, we define the ethnicity variable based on mother tongue of the mother following Güneş (2015). In the data set, there are four ethnicity groups: Turkish, Kurdish, Arabic and others. We create four dummy variables based on these ethnicity groups. For instance, the variable 'Turkish' is equal to 1 if the mother tongue of the mother is Turkish and 0 otherwise. The other ethnicity variables are defined in a similar manner. However, after establishing the variance-covariance matrices for each variable and computing the Variance Inflation Factors (VIF) of each variable, we find that the VIFs of 'Turkish' and 'Kurdish' are very high (16.5 for Turkish and 15.2 for Kurdish, which are above the acceptable threshold level of 10), hence including ethnicity variables in the regression analysis may lead to a multicollinearity problem, which results with high standard errors. Therefore, we exclude the variables of ethnicity from the regression analysis.

\subsection{Summary of Descriptive Statistics}

Table 2 below displays the descriptive statistics of explanatory variables differentiated with respect to the children's standardized height measures. In doing so, we sub-group the children's standardized height measures across $25^{\text {th }}, 50^{\text {th }}, 75^{\text {th }}$ and $99^{\text {th }}$ quantiles.

\section{<Table 2. Descriptive Statistics> about here}

Regarding the anthropometrics of the child, descriptive statistics clearly suggest that children at higher quintiles of standardized height have higher birthweights and the differences in birthweight across the different quantiles are statistically significant. For instance, while the mean birthweight in $25^{\text {th }}$ quantile is 2948 grams, it gradually reaches 3183 grams in the $99^{\text {th }}$ quantile. Likewise, we observe a significant variation across different quantiles regarding the birth order of the child. Descriptive statistics indicate that earlier born children on average have better standardized height measures.

For mother's height, we observe a gradual, but small increase across the different quantiles of child's standardized height. However, multivariate tests of means suggest that the differences 
in mother's height in different quantiles do not significantly differ from each other.

Regarding the nutrition variables, first we observe a monotonic increase in nutrition index across increasing quantiles of the standardized height. However, for the breastfeeding dummy, we only observe a significant variation only between the $25^{\text {th }}$ and $50^{\text {th }}$ quantiles. The significant difference disappears for the higher quantiles, which indicates that being breastfed may not explain the variations in standardized height significantly. For the crèche/pre-school variable, we observe a significant variation in the lowest and the highest quantiles that we consider: on average the proportion of children who attend pre-school is 5 percent in the $25^{\text {th }}$ quantile of measured standardized height, while this proportion amounts to nearly 9 percent in the highest quantile.

For the region dummy, descriptive statistics point out that on average children who live in urban areas have superior standardized height measures. For example, 65 percent of the children whose standardized height measures fall in the $25^{\text {th }}$ quantile live in urban areas while for the highest quantile, this rate increases to 74 percent. Thus, descriptive statistics support our expectations that children living in urban areas tend to have better health outcomes as their caretakers make use of the better infrastructure and have better access to health care services compared to those children residing in rural areas. For the wealth index, we observe a gradual rise across quantiles: the average wealth index is 2.142 and 2.611 in $25^{\text {th }}$ and $99^{\text {th }}$ quantiles respectively. Likewise, for both mothers and fathers, years of schooling increases monotonically across different quantiles therefore, descriptive statistics validate our prediction that when children come from wealthier families and have better educated parents, they tend to have better health outcomes.

Regarding the parents' employment statuses, we observe that children of employed parents have better standardized heights relative to the unemployed and inactive parents. Furthermore, the descriptive statistics confirm our expectations regarding the occupation type of mothers, in the sense that the proportion of irregular self-employed and unpaid family worker mothers decreases in higher quantiles, while that of regular wage and salary earner government employee mothers increases.

Descriptive statistics clearly indicate that as households become more crowded, children tend to have lower standardized height measures. Additionally, the mean of female headship variable appears to be volatile across different quantiles indicating that whether the father is present in the household or not is not a good predictor of child health. Lastly, regarding the ethnicity variables, we observe that a larger proportion of Kurdish and Arabic children fall into the lower 
quantiles of standardized height, whereas Turkish children tend to have better standardized height measures.

\section{Model and Empirical Results}

We apply classical regression techniques in order to estimate the association between family's socioeconomic status and child's health outcomes. For this study, ordinary least squares (OLS) estimation is appropriate and will turn out consistent and efficient results as we do not expect any reverse causality problem. As Case et al. (2002) suggest, children's poorer health cannot explain lower household socioeconomic status since in general, children cannot contribute to the household income. Similarly, in our analysis, lower standardized heights of children 7-59 months old cannot explain lower household wealth or socioeconomic status. In addition, we control for the multicollinearity problem by creating the variance-covariance matrix and by calculating the VIFs of the variables. We exclude the variables (the ethnicity dummies) which have high VIFs (greater than 10). We establish our model as follows:

$$
Y_{i}=\delta+C A_{i} \alpha_{1}+N_{i} \alpha_{2}+R_{i} \alpha_{3}+O S E F_{i} \alpha_{4}+E_{i} \alpha_{5}+E M P_{i} \alpha_{6}+W_{i} \alpha_{7}+\varepsilon_{i}
$$

In equation (3) $\mathrm{Y}_{\mathrm{i}}$ refers to the health outcome of child i, namely the standardized height of the child i. The variable $\mathrm{CA}_{\mathrm{i}}$ shows child i's exogenous anthropometrics, namely his/her birth weight and birth order. It also includes the mother's height as an exogenous factor reflecting genetics. The vector $\mathrm{N}$ includes the nutrition indicators for the child, i.e. whether the child is (or was) breastfed and the nutrition index that we construct based on the child's age (in months). The variable $\mathrm{R}$ indicates the region where the child lives. The vector OSEF comprises of specific variables including whether the child is sent to pre-school/crèche or not and those that are expected to reflect family's socioeconomic status, such as the number of household members, and whether the head of the household is female or not. The variable $\mathrm{E}_{\mathrm{i}}$ stands for the education status of both parents of child $i$, measured by years of schooling. The variable $\mathrm{EMP}_{\mathrm{i}}$ refers to the employment status of both parents of child $\mathrm{i}$, as well as the mother's occupation type if she is employed. The variable $\mathrm{W}_{\mathrm{i}}$ is the wealth index of the household in which child i lives. Finally, the vector $\varepsilon$ for each child i embodies unobserved factors such as mother's IQ score.

We first include the unambiguously exogenous variables into our model such as the child's birth order and birth weight as well as mother's height. Then we include the other control 
variables gradually into our model in order to see how the impact of each variable changes when we control for other factors that may affect the child's standardized height. In total, we have seven distinct regression models as given in Table 3. Although no perfect relationship has been detected between the control variables, it is important to note that, two or more control variables may have joint impact on child's health outcome. For example, the likelihood of better nutrition might be higher for a child from a wealthier family with more educated parents. Therefore, one should be careful in the interpretation of the estimated coefficients in that they show the controlled associations between the each independent variable and the dependent variable, rather than a causal relationship between them.

\section{<Table 3. Estimation Results> about here}

Table 3 shows that child's anthropometric measures significantly affect the child's standardized height measure. When we include only the child's birth order and birthweight together with the mother's height in our regression model, we observe that child's birthweight positively and significantly affects the child's standardized height. For instance, a one-gram increase in child's birthweight leads to a 0.00147 unit increase in child's standardized height. The regression results also reveal that child's birth order is negatively associated with child's standardized height, which implies that first-born children predominantly have better standardized height measures. The significant effects of the child's anthropometrics remain intact when we control the other factors. Therefore, one can conclude that child's exogenous anthropometrics are important determinants of the child's health. Lastly, although mother's height is positively associated with the child's standardized height, the relationship is not statistically significant (which may be because there is not a significant variation in mothers' height across different standardized height measures of the children as shown in Table 2).

Our results do not provide any significant association between breastfeeding and child's standardized height, either. However, we observe that having proper nutrition positively affects the child's standardized height. For instance, one unit rise in the nutrition index increases the child's standardized height leads to a 1.553 unit increase in child's standardized height. ${ }^{7}$ Yet, the significant impact of nutrition index disappears when we control for the parents' employment statuses and the wealth index.

\footnotetext{
${ }^{7}$ Arimond and Ruel (2004) also show that dietary diversity is strongly associated with child's height for age zscore after controlling for selected indicators of parents's socioeconomic status, using DHS data from 11 developing countries.
} 
The dummy variable for region is found to be positively significant in all of the models in which it is included. In Table 3, in model (7), where we include all of the control factors into our regression analysis, the variable "Urban" continues to be positively significant. Model (7) reveals that if the child lives in urban area, his/her standardized height increases by 0.648 units. Therefore, living in urban areas is beneficial for the child's health, mainly because of the better infrastructure, availability of sanitation, water and electricity facilities, as well as convenient access to health care services.

Table 3 reveals that children from crowded families have lower standardized heights. The negative relationship between number of household members and child's standardized height is significant in Model (4) in Table 3, but this significant association disappears when we include the parents' education levels, employment statuses and wealth index. From Model (4) and Model (5), one can infer that the children from the households where female is the head of the household have significantly lower standardized heights compared to the households where father is the household head. However, the significant relationship disappears when we control for parents' employment statuses and wealth index. The regression results do not suggest any significant relationship between the children's standardized height measures and their preschool/crèche attendance, which may arise due to the fact that pre-school/crèche attendance is quite low in Turkey. ${ }^{8}$

Regression results also suggest that mother's years of schooling significantly increases the child's standardized height, while father's years of schooling have no impact on child's standardized height. It is noteworthy to state that significant impact of mother's education on child's standardized height also disappears when we control for the wealth index ${ }^{9}$. Next, estimation results indicate that employment status of fathers has no effect on child's standardized height. In addition, we observe that when the mother works as an unpaid family worker or when she is self-employed with irregular (or unrecorded) working hours and income (presumably finding work as a domestic servant), her child has a worse standardized height measure compared to other occupation groups. Similarly, children of unemployed mothers have poorer health outcomes, as well. Finally, we include the wealth index, which ranges from 1 to

\footnotetext{
${ }^{8}$ As of 2013, overall pre-school attendance in Turkey is at 28 percent, while the pre-school attendance rate for the OECD countries average is 82 percent. In Turkey, among the 3 -year-olds, 7 percent attend pre-school or crèches, while the rate is 36 percent for 4-year-olds, and 74 percent for 5-year-olds (Saracoğlu and Karaoğlan 2016).

${ }^{9} \mathrm{We}$ also apply quantile regression techniques in order to test the effect of mother's completed years of schooling on child's health. Quantile regression results provide robust evidence that mother's education level has significant impact on children with approximately median value of the standardized height (i.e. between the 40th and 50th quantiles), or in other words, on children with average health outcomes. This significant effect is maintained even if we control for the household's wealth index. Quantile regression results are available upon request.
} 
5. Higher wealth has a positive impact on child's standardized height, however the effect is insignificant. This may result due to the fact that in our regressions, part of the effects controlled by the wealth index are already captured by the urban dummy, which has a positive and significant association with the child's standardized health measure.

\section{Conclusion}

Previous literature has established that intergenerational transmission of economic status may work via adult health, and that adult health is linked to childhood circumstances, including childhood health status. The research focusing on the mechanisms of intergenerational transmission of economic status emphasizes that child health is important not only for its own sake, but also because it enhances the future outcomes of the child. In this context, it has been argued that parents' socioeconomic status ultimately has an impact on an individual's future educational and labor market outcomes through its effects on childhood health status. Within these ideas, this study investigates the impact of parents' socioeconomic status on child's health outcome, primarily the child's standardized height which is derived from the height-for-age zscore of the child. Our study is the first to investigate the association between the child's health and parents' socioeconomic status (SES) as well as child's anthropometrics at birth, nutrition indicators and pre-school/crèche attendance of the child using the most recent round of DHS data set for Turkey. Apart from parents' wealth, we also include the parents' education levels, employment statuses, number of people in the household, female headship, and the region that the household resides (urban/rural) as indicators of parents' SES.

First and foremost, our results suggest that a child who lives in an urban area significantly has better health outcomes, irrespective of his/her initial anthropometrics and genetics, or regardless of the family's other socioeconomic status indicators. Therefore, we conclude that living conditions and infrastructure such as sanitation, access to clean water, and availability of electricity, which are under the control of the local governments, as well as access to health care services must be improved for better child health, especially in rural areas where the availability of such services might be limited compared to urban areas.

Second, our results clearly indicate that higher birthweight is positively associated with child's better future health, irrespective of the family's socioeconomic status. Having low birthweight is indicative of prenatal circumstances and previous studies have shown that infants born with low birthweight are more likely to be stunted or experience deficits in height at later ages 
(Krishna et al. 2016). Therefore, mothers should avoid risky behaviors such as smoking, using alcohol or drugs during their pregnancy, since these behaviors directly affect the infant's health in utero. Additionally, the mother should also receive proper nutrition during pregnancy for the child to have better birthweight. The representatives of the Ministry of Health as well as the Ministry of Family and Social Policies, local governments, or relevant non-governmental organizations are expected to communicate the hazards of risky health behaviors and the benefits of proper nutrition to the public more efficiently, and furthermore, nutritional supplementation should be made available to the expectant women whenever necessary.

Third, by creating a specific nutrition index for each infant or child in different age groups, we find that proper and diverse nutrition at each stage of childhood is significantly beneficial for the child's health. Correspondingly, comprehensive government policies must be designed and implemented to provide infants and young children (especially from low socioeconomic backgrounds) with adequate and diverse nutrition, and ameliorate their nutritional intake. For instance, nutrition subsidy programs for specific alimentation may be administered to households of low socioeconomic status. In addition, we find that although in general, child's health is positively related to breastfeeding, the association is not significant for children of 7 to 59 months. This finding tells us that for children older than 6 months old, the impact of proper and diverse nutrition may dominate the positive effect of breastfeeding on child's health.

Fourth, we find that mother's education level for the most part has a positive and significant impact on child's health. This may arise because of the fact that more educated mothers have better access to and process more information for better health, and they make better use of available health care services for their children. Hence, the government is expected to take widespread initiatives and develop policies to increase women's years of schooling, and for this purpose present incentives especially to families with low socioeconomic status so that their daughters can participate in and complete, at the very least, compulsory schooling. In that respect, the adverse effects of the low socioeconomic status transmitted from previous generations on child health may in part be overcome by educated mothers, thus breaking the cycle. In addition, when a mother has a university or higher degree, evidently her child has better health. Thus, the government should also increase the opportunities for women so that they will be able to continue to higher education (opportunities may include free or subsidized student housing for women provided by the government agencies).

Additionally, our results clearly indicate that the children, whose mothers are unemployed or do not have regular jobs, have worse health conditions. On the contrary, when the mother has 
a regular job, the child comparably has better health; however the impact is not significant. Hence, more regular (rather than irregular or informal) employment opportunities for women should be made available to lower income families, for example, by supporting and encouraging them to participate in apprenticeship or job-training programs.

In conclusion, this study is the first to examine the impact of a full range of SES indicators together with nutrition indicators as well as the mother's and child's anthropometrics, on child's health. Although we cannot detect the causal effects of each indicator on child's health due to the formation of the data set and due to the lack of relevant exogenous proxies for each control variable, we are able to detect the association between child's health and these controls. This allows us to infer relevant policies. However, it is noteworthy to state that these implications would have been better interpreted had we had access to longitudinal data and had the opportunity to test the effect of variations in household's SES indicators (for instance, the mother is unemployed in one period, and she is regularly employed in the next period) as well as the child's nutrition indices, rather than a cross-section one. But unfortunately, for the case of Turkey such medium- or long-term panel data regarding adult socioeconomic status and the child's health conditions are not collected, hence such detailed and more insightful research on the determinants of health status across different ages of the child is not yet possible. 


\section{References}

Aber, J.L, N.G. Bennett, D.C. Conley, and J. Li. 1997. "The effects of poverty on child health and development." Annual Review of Public Health 18: 463-83.

Abuya, B.A., J. Ciera, and E. Kimani-Murage. 2012. "Effect of mother's education on child's nutritional status in the slums of Nairobi." BMC Pediatrics 12: 80. Open access article.

Adler, N. E., T. Boyce, M. A. Chesney, S. Cohen, S. Folkman, R. L. Kahn and S. L. Syme. 1994. "Socioeconomic Status and Health: The Challenge of the Gradient." American Psychologist 49 (1): 15-24.

Almond, D. and J. Currie. 2010. "Human Capital Development before Age Five." NBER Working Paper No. 15827.

Amin, R., N.M. Shah, and S. Becker. 2010. "Socioeconomic factors differentiating maternal and child health-seeking behavior in rural Bangladesh: A cross-sectional analysis." International Journal for Equity in Health 9: 9. Open access article.

Anderson, L.M., C. Shinn, M.T. Fullilove, S.C. Scrimshaw, J.E. Fielding, J. Normand, V.G. Carande-Kulis, and the Task force on Community Preventive Services. 2003. "The Effectiveness of Early Childhood Development Programs: A Systematic Review." American Journal of Preventive Medicine 34 (3S): 32-46.

Arimond, M. and M. T. Ruel. 2004. "Dietary Diversity is associated with Child Nutritional Status: Evidence from 11 Demographic and Health Surveys." The Journal of Nutrition 134: 2579-2585.

Arora, S. 2001. "Health, Human Productivity, and Long-term Economic Growth." The Journal of Economic History 61 (3): 699-749.

Assaad, R., C. Krafft, N. B. Hassine and D. Salehi-Isfahani. 2012. "Inequality of Opportunity in Child Health in the Arab World and Turkey." Middle East Development Journal 4 (2): $1-37$

Barro, R.J. 2001. "Human Capital and Growth.” American Economic Review 91 (2): 12-17.

Becker, G. S. 1962. "Investment in Human Capital: A Theoretical Analysis." Journal of Political Economy 70 (5): 9-49.

Benhabib, J. and M.M. Spiegel. 1994. "The role of human capital in economic development Evidence from aggregate cross-country data." Journal of Monetary Economics 34: 143173.

Ben-Porath, Y. 1967. "The Production of Human Capital and the Life Cycle of Earnings." Journal of Political Economy 75 (4): 352-365.

Blau, D. M. 1999. "The Effect of Income on Child Development." The Review of Economics and Statistics 81 (2): 261-276.

Bradley, R. H. and R. F. Corwyn. 2002. "Socioeconomic Status and Child Development." Annual Review of Psychology 53: 371-399.

Brooks-Gunn, J. and G.J. Duncan. 1997. "The effects of poverty on children." The Future of Children 7 (2): 55-71.

Carneiro, P. and J. J. Heckman. 2003. "Human Capital Policy.” NBER Working Paper No. 9495.

Case, A., D. Lubotsky, and C. Paxson. 2002. "Economic Status and Health in Childhood: The 
Origins of the Gradient.” American Economic Review 92 (5): 1308-1334.

Case, A., and C. Paxson. 2002. "Parental Behavior and Child Health." Health Affairs 21 (2): 164-178.

Case, A., A. Fertig, and C. Paxson. 2005. "The Lasting Impact of Childhood Health and Circumstance." Journal of Health Economics 24 (2): 365-389.

Chen, E. 2004. "Why socioeconomic status affects the health of children: A psychosocial perspective." Current Directions in Psychological Science 13 (3): 112-115.

Chen, Y. and H. Li. 2009. "Mother's education and child health: Is there a nurturing effect?" Journal of Health Economics 28: 413-426.

Cohen, D. and M. Soto. 2007. "Growth and human capital: good data, good results." Journal of Economic Growth 12: 51-76.

Conroy, K., M. Sandel, and B. Zuckerman. 2010. "Poverty Grown Up: How Childhood Socioeconomic Status Impacts Adult Health." Journal of Developmental \& Behavioral Pediatrics 31: 154-160.

Conti, G., and J. J. Heckman. 2012. "The Economics of Child Well-Being.” IZA Discussion Paper No. 6930.

Currie, J., and R. Hyson. 1999. "Is the Impact of Health Shocks Cushioned by Socioeconomic Status? The Case of Low Birthweight.” American Economic Review 89 (2): 245-250.

Currie, J. 2009. "Healthy, Wealthy, and Wise: Socioeconomic Status, Poor Health in Childhood, and Human Capital Development." Journal of Economic Literature 47 (1): 87-122.

Desai, S., and S. Alva. 1998. "Maternal Education and Child Health: Is there a Strong Causal Relationship?” Demography 35 (1): 71-81.

Duncan, G. J., J. Brooks-Gunn and P. K. Klebanov. 1994. "Economic Deprivation and Early Childhood Development.” Child Development 65 (2): 296-318.

Durkin, M.S.,S. Islam, Z.M. Hassan, and S.S. Zaman. 1994.”Measures of socioeconomic status for child health research: Comparative results from Bangladesh and Pakistan". Social Science and Medicine 38 (9): 1289-1297.

Filmer, D. and L.H. Pritchett. 2001. "Estimating wealth effects without expenditure data-or tears: An application to educational enrollments in States of India." Demography 38 (1): 115-132.

Finch, B.K. and A.N. Beck. 2011. "Socio-economic status and z-score standardized height-forage of U.S.-born children (ages 2-6)." Economics and Human Biology 9: 272-276.

Glewwe, P. 1999. "Why Does Mother's Schooling Raise Child Health in Developing Countries?: Evidence from Morocco." The Journal of Human Resources 34 (1): 124159.

Grantham-McGregor, S., Y. B. Cheung, S. Cueto, P. Glewwe, L. Richter, B.Strupp, aand the International Child Development Steering Group. 2007. "Developmental potential in the first 5 years for children in developing countries." Lancet 369: 60-70.

Grossman, M. 1972. "On the Concept of Health Capital and the Demand for Health.” Journal of Political Economy 80 (2): 223-255.

Grossman, M. 2000. “The Human Capital Model.” Handbook of Health Economics Vol. 1 
edited by A.J. Culyer and J.P. Newhouse. Elsevier Science: Amsterdam, the Netherlands.

Güneş, P.M. 2015. "The role of maternal education in child health: Evidence from a compulsory schooling law." Economics of Education Review 47: 1-16.

Gyimah-Brempong, K. and M. Wilson. 2004. "Health human capital and economic growth in Sub-Saharan African and OECD Countries." The Quarterly Review of Economics and Finance 44: 296-320.

Hauser, R. M. 1994. "Measuring Socioeconomic Status in Studies of Child Development." Child Development 65 (6): 1541-1545.

Heckman, J. J. and D. V. Masterov. 2007. "The Productivity Argument in Investing in Young Children." Review of Agricultural Economics 29 (3): 446-493.

Knudsen, E. I., J. J. Heckman, J. L. Cameron, and J. P. Shonkoff. 2006. "Economic, Neurobiological, and Behavioral Perspectives on Building America's Future Workforce." Proceedings of the National Academy of Sciences (PNAS) 103 (27): 10155-10162.

Krishna, A., G. Fink, L.F. Berman, and S.V.Subramanian. 2016. "Short- and long-run associations between birth weight and children's height." Economics and Human Biology 21: 156-166.

Liu, G. G., W.H. Dow, A.Z. Fu, J. Akin and P. Lance. 2008. "Income productivity in China: On the role of health." Journal of Health Economics 27: 27-44.

Maggi, S., L. J. Irwin, A. Siddiqi and C. Hertzman. 2010. "The Social Determinants of Early Child Development: An Overview." Journal of Paediatrics and Child Health 46 (11): 627-635.

Mankiw, N. G., D. Romer, and D. N. Weil. 1992. "A Contribution to the Empirics of Economic Growth.” The Quarterly Journal of Economics 107 (2): 407-437.

McDonald, S. and J.Roberts. 2002. "Growth and multiple forms of human capital in an augmented Solow model: a panel data investigation." Economics Letters 74: 271-276.

Meer, J., D.L. Miller and H.S. Rosen. 2003. "Exploring the health-wealth nexus." Journal of Health Economics 22: 713-730.

Mushkin,S.J. 1962. "Health as an Investment." Journal of Political Economy 70 (5/2): 129-157.

Pradhan, M., D. E. Sahn, and S. D. Younger. 2003. "Decomposing World Health Inequality.” Journal of Health Economics 22 (2): 271-293.

Saracoğlu, D.Ş., and D. Karaoğlan. 2016. "Early Childhood Development and Human Capital Formation: The Case of Turkey in Global Perspective." METU Department of Economics ERC Working Paper No. 16/05.

Schultz, T.W. 1961. "Investment in Human Capital." The American Economic Review L1 (1): $1-17$.

Schultz, T.P. 2002. "Wage Gains Associated with Height as a form of Health Human Capital." Yale University Center Discussion Paper No. 841.

Schultz, T.P. 2003. "Human capital, schooling and health." Economics and Human Biology 1: 207-221.

Schultz, T.P. 2005. "Productive Benefits of Health: Evidence from Low-Income Countries." 
IZA Discussion Paper No. 1482.

Sears, W. and M. Sears. 2003. The Baby Book: Everything you need to know about your baby from birth to age two. Little, Brown and Company. New York: NY.

Shastry, G.K. and D.N. Weil. 2003. "How much of Cross-country Income Variation is explained by Health?" Journal of the European Economic Association 1 (2-3): 387-396.

Smith, J.P. 2009. "The impact of childhood health on adult labor market outcomes." The Review of Economics and Statistics 91 (3): 478-489.

Taylor, B. A., E. Dearing and K. McCartney. 2004. "Incomes and Outcomes in Early Childhood." The Journal of Human Resources 39 (4): 980-1007.

Thomas,D., J. Strauss, and M.-H. Henriques. 1991. "How Does Mother's Education Affect Child's Height?" The Journal of Human Resources 26 (2): 183-211.

Von Reuden U., A. Gosch, L. Rajmil, C. Bisegger, U. Ravens-Sieberer, the European KIDSCREEN Group. 2006. "Socioeconomic determinants of health related quality of life in childhood and adolescence: results from a European study." Journal of Epidemiol Community Health 60: 130-135.

Wamani, H., T. Tylleskar, A.N. Astrom, J.K. Tumwine, and S. Peterson. 2004. "Mothers' education but not fathers' education, household assets or land ownership is the best predictor of child health inequalities in rural Uganda." International Journal for Equity in Health 3: 9. Open access article.

Wamani, H., A. N. Astrom, S. Peterson, J. K. Tumwine and T. Tylleskar. 2007. "Boys Are More Stunted than Girls in Sub-Saharan Africa: A Meta-Analysis of 16 Demographic and Health Surveys." BMC Pediatrics 7: 17. Open access article.

Zere, E., and D. McIntyre. 2003. "Inequities in Under-Five Child Malnutrition in South Africa." International Journal for Equity in Health 2 (7): 1-10.

Zong, X.-N., H. Li, H.-H. Wu, and Y.-Q. Zhang. 2015. "Socioeconomic development and secular trend in height in China." Economics and Human Biology 19: 258-264. 


\section{TABLES IN TEXT}

Table 1. Infant feeding and food groups in Turkey DHS 2013*

\begin{tabular}{|c|c|c|c|c|}
\hline & 7-9 mo. & 9-12 mo. & 12-18 mo. & $18 \mathrm{mo}$. and older \\
\hline \multicolumn{5}{|l|}{ Fresh vegetables fruits } \\
\hline \multicolumn{5}{|l|}{ Cereals, grains } \\
\hline \multicolumn{5}{|l|}{ Yogurt } \\
\hline \multicolumn{5}{|l|}{ Cheese } \\
\hline \multicolumn{5}{|l|}{ Red meat } \\
\hline \multicolumn{5}{|l|}{ Chicken } \\
\hline \multicolumn{5}{|l|}{ Dry legumes } \\
\hline \multicolumn{5}{|l|}{ Milk } \\
\hline \multicolumn{5}{|l|}{ Whole egg } \\
\hline \multicolumn{5}{|l|}{ Fish } \\
\hline \multicolumn{5}{|l|}{ Bread } \\
\hline \multicolumn{5}{|l|}{ Soup } \\
\hline No. of food groups & 2 & 7 & 11 & 12 \\
\hline
\end{tabular}

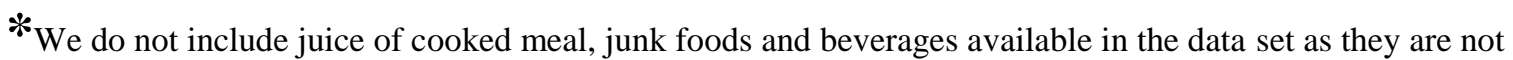
representative of nutrition.

Source: Turkey DHS (2013); Sears and Sears (2003) 
Table 2. Descriptive Statistics

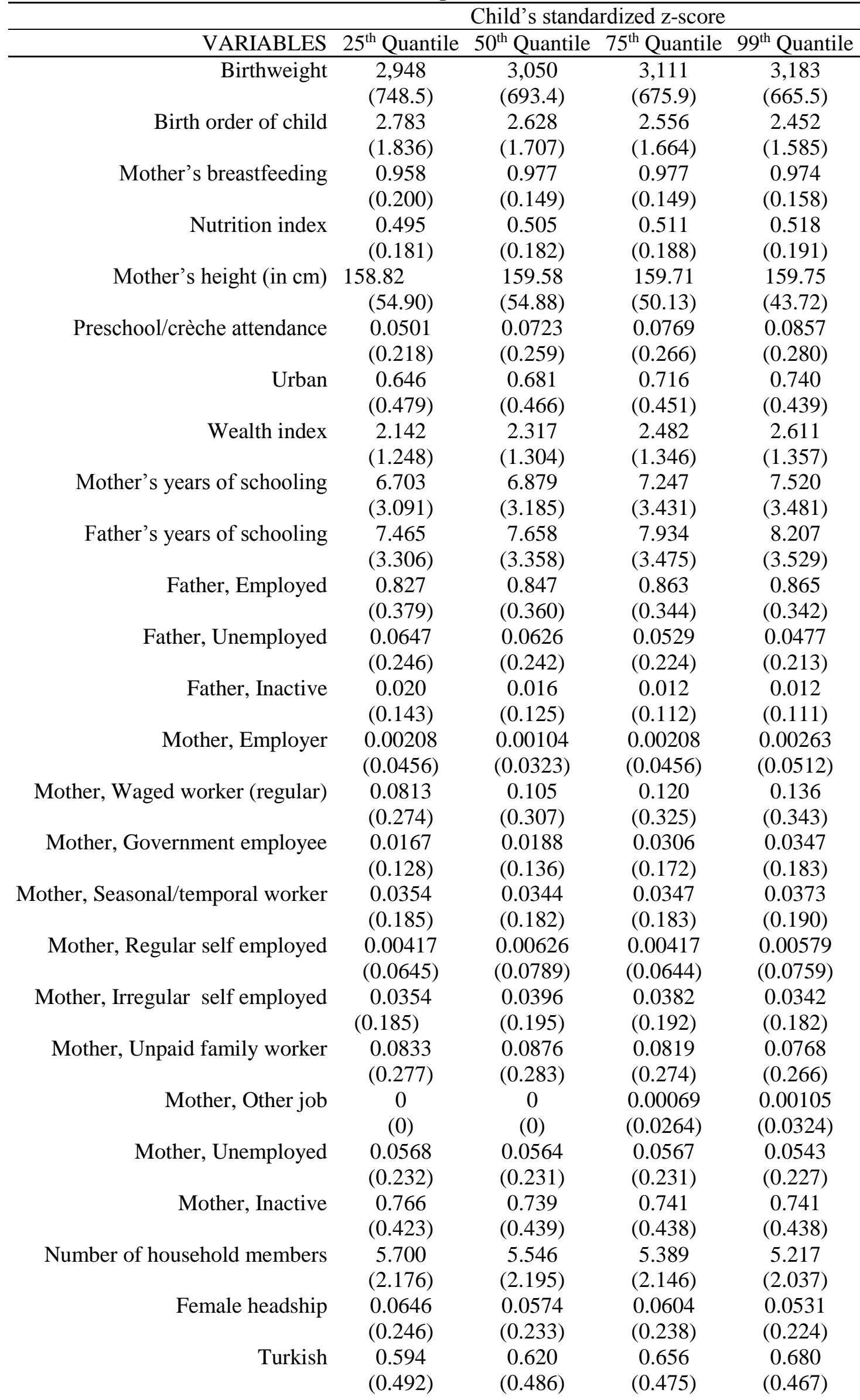




$\begin{array}{ccccc}\text { Kurdish } & 0.354 & 0.336 & 0.298 & 0.276 \\ & (0.479) & (0.473) & (0.458) & (0.447) \\ \text { Arabic } & 0.0417 & 0.0365 & 0.0361 & 0.0337 \\ & (0.200) & (0.188) & (0.187) & (0.180)\end{array}$


Table 3. Estimation Results

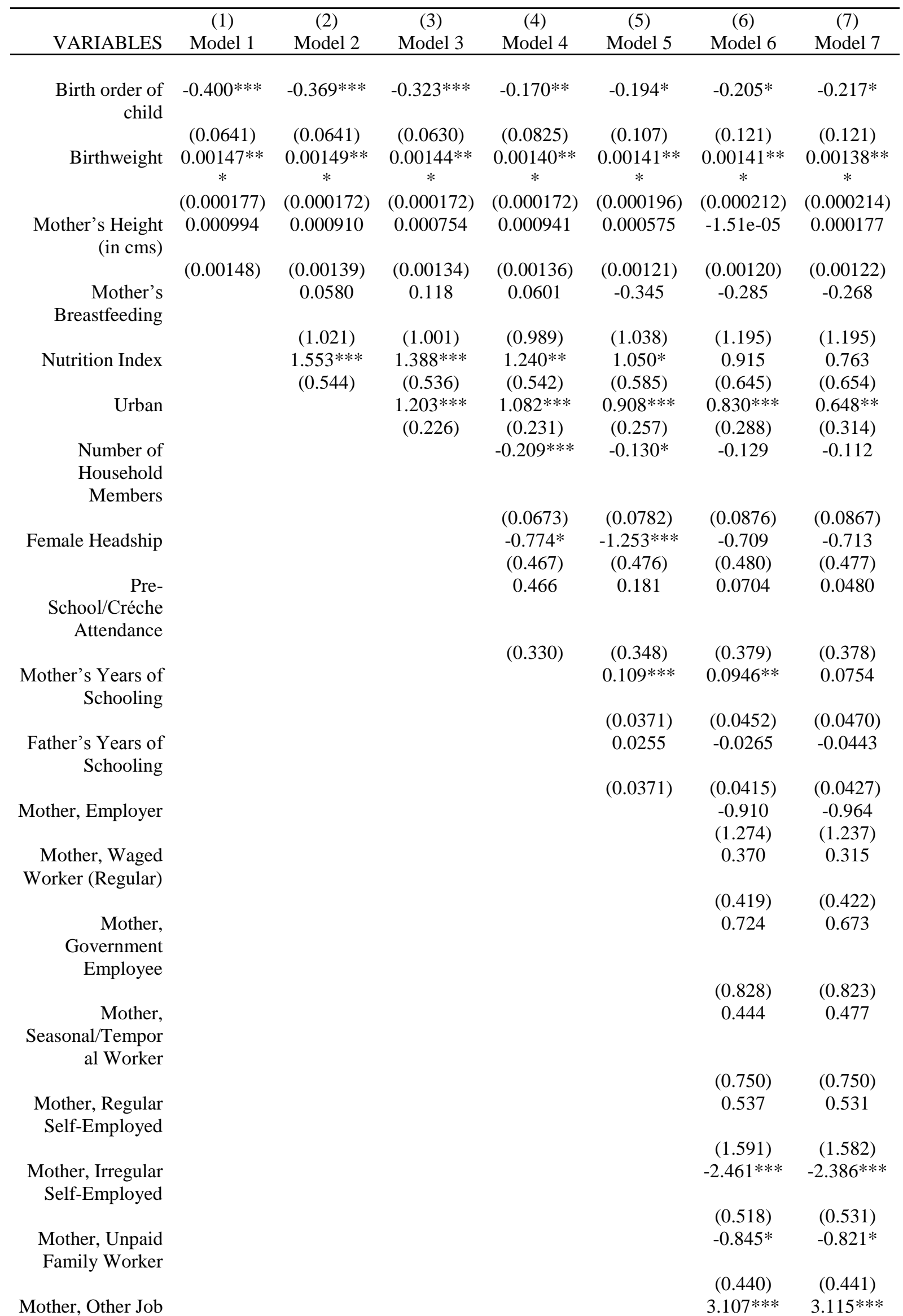


Mother,

Unemployed

Father, Employed

Father,

Unemployed

Wealth Index

Constant

\begin{tabular}{|c|c|c|c|c|c|c|}
\hline & & & & & $\begin{array}{c}(0.330) \\
-1.133 *\end{array}$ & $\begin{array}{c}(0.331) \\
-1.055^{*}\end{array}$ \\
\hline & & & & & $\begin{array}{c}(0.579) \\
0.00256 \\
(1.228) \\
-0.566\end{array}$ & $\begin{array}{c}(0.587) \\
0.0177 \\
(1.217) \\
-0.518\end{array}$ \\
\hline & & & & & (1.360) & $\begin{array}{c}(1.352) \\
0.196 \\
(0.127)\end{array}$ \\
\hline $\begin{array}{l}.39 * * * \\
0.641)\end{array}$ & $\begin{array}{c}79.41 * * * \\
(1.257)\end{array}$ & $\begin{array}{c}78.60 * * * \\
(1.245)\end{array}$ & $\begin{array}{c}79.63 * * * \\
(1.280)\end{array}$ & $\begin{array}{c}79.02 * * * \\
(1.382)\end{array}$ & $\begin{array}{c}79.84 * * * \\
(1.906)\end{array}$ & $\begin{array}{c}79.79 * * * \\
(1.897)\end{array}$ \\
\hline 1,811 & 1,784 & 1,784 & 1,776 & 1,548 & 1,294 & 1,294 \\
\hline 0.069 & 0.076 & 0.090 & 0.098 & 0.100 & 0.107 & 0.108 \\
\hline
\end{tabular}

Robust standard errors in parentheses

$* * * \mathrm{p}<0.01, * * \mathrm{p}<0.05, * \mathrm{p}<0.1$ 